\title{
Developing Student Enthusiasm: Interaction With Professionals In A Professional Environment
}

\author{
Gadis J. Dillon, (Email: dillon@oakland.edu), Oakland University
}

\begin{abstract}
While not necessarily a primary responsibility, most business faculty members work to build student enthusiasm for the faculty member's discipline. This manuscript describes a project intended to accomplish that objective, as well as, several other objectives. Specifically, it is used in the Introductory Accounting course, but could be adapted to other disciplines as well. Groups of students visited and interviewed accounting professionals in their offices. The students then prepared and presented written and oral reports. Benefits included exposing students to real-world environments and to successful professionals, and providing opportunities to practice team-building and oral and written communication skills. In a post-assignment survey, both students and interview subjects felt the assignment was a valuable experience. Further, a number of students demonstrated a greater level of enthusiasm for the accounting major.
\end{abstract}

\section{INTRODUCTION}

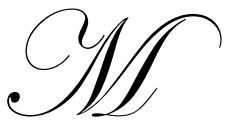

ost faculty members continually seek ways to improve the education process. In addition to better means for delivering technical subject matter, they often address other aspects of the educational process such as increasing students' awareness/knowledge of the business environment, incorporating student development activities such as team-building exercises and written and oral communication opportunities, and developing enthusiasm for their discipline.

These issues may be especially significant to the Introductory Accounting courses. These courses are usually a student's first exposure to the accounting discipline and to business in general. Attitudes developed in the Introductory Accounting course are often important for determining the student's attitude toward future course-work and careers. As such, it is important that the course develop positive attitudes toward business and accounting careers.

This paper describes an assignment, included in an Introductory Accounting course, intended to address the above considerations. The specific elements of this assignment were developed for the Introductory Accounting course, in light of the circumstances at the author's university. However, the general concept should transfer well to a variety of introductory courses in other disciplines at almost all types of institutions.

\section{THE ASSIGNMENT}

As at most institutions, members of the faculty at the author's university are sensitive to the above issues, and have addressed ways that the educational process can be improved. As a result of these discussions, the author developed the project described here and has assigned it for several years. 


\section{Project Objectives}

As the project development evolved, a number of specific objectives were identified. The assignment was then structured to meet those objectives. The primary objective was to expose students to real-world situations, not just classroom and textbook information, and give students an opportunity to observe and interact with individuals who have achieved a high level of success in the business community. These individuals may be viewed as role models, providing incentive for students to apply themselves and achieve similar success. They may also influence students to develop a more positive attitude and enthusiasm toward accounting as a career.

The nature of the exercise, a group project culminating in written and oral presentations, also provides a team-building experience and an opportunity to practice written and oral communications skills. Further, the exercise increases the interactions of the university with the business community.

\section{Institution-Specific Attributes}

Before describing the specific project, the attributes of the author's university and its Department of Accounting are briefly discussed. These attributes dictated the specific details of this assignment. Other institutions may find it necessary to modify the project details to conform to their situations.

The university is a regional university located in the suburbs of a major metropolitan area. Most students commute to campus; less than ten percent live on campus. A significant proportion of students are first generation in college. The School of Business Administration and the Department of Accounting experienced enrollment declines in late 1990s. Recent enrollment increases have occurred, but have not raised enrollments to 1990 levels. Recruiting good students continues to be an important issue.

Offices of all the Big 4 and several large national and regional CPA firms, as well as, the corporate offices of a number of large companies are nearby. Of particular importance, the department has an active Advisory Board, consisting of partners of national, regional and local CPA firms and individuals with very responsible positions in industry and government. This board is active in providing input to the faculty and support for the department.

\section{Project Details}

The objective of the exercise is to have students visit successful accountants in their offices, and to prepare and present written and oral reports on that visit. Specifically, members of the Accounting Advisory Board are asked to host small groups of students in their offices for a one-hour visit/interview.

Especially since most students at the author's university have limited exposure to professionals and corporate executives, the visits to the offices are considered a particularly valuable learning experience. Further, having students interact with very successful individuals who hold responsible positions is also important. For this project, the author is especially fortunate that the members of the Advisory Board are willing to participate. The board members themselves, rather than human resource professionals or junior staff members, visit with the students. This increases the quality of the experience for the students.

Given the interview subjects' positions and time constraints, a considerable amount of administrative preparation is necessary. Details to be considered include: 1) Contacting the prospective interview subjects and obtaining their agreement to participate; 2) Developing detailed instructions for student groups; 3) Assigning students to groups and groups to interview subjects; and 4) Follow-up evaluation and communication. Each is described below in detail. 


\section{Contacting Interview Subjects And Obtaining Their Agreement To Participate}

The first semester this project was assigned, the departmental chairperson made the initial contact with the Advisory Board members. She sent a letter (drafted by the author) to each board member, briefly describing the assignment and inquiring if the board member would be willing to participate. In subsequent semesters, the author has made the initial request, about one month before the beginning of the semester. Most board members respond positively. In fact, most are quite enthusiastic about participating.

After the initial contact and agreement to participate, the author then sends a confirmation letter to each interview subject, expressing thanks for participating and indicating that the student group would be contacting the interview subject soon. The assignment sheet (described below) is included in the letter. A copy of their subject's confirmation letter is given to each group, to identify their subject and provide contact information. It also provides a model for an appropriate business letter. After the projects are completed, the author sends a thank-you letter and a survey instrument to each participant. Further, each group is required to send a thank-you letter to their interview subject.

In identifying interview subjects, the author is careful to avoid professional recruiters. Recruiters often have different motivations, and may not provide as accurate a picture of professional activities. Institutions without an active Advisory Board may find it necessary to expend additional efforts to find appropriate interview subjects. However, the author's experience at several institutions is that many professionals are quite willing (even eager) to work with students, so long as the time commitment is relatively limited.

\section{Developing Detailed Instructions For Student Groups}

The detailed instruction sheet for this project is shown in Exhibit I. These instructions have been developed based on the project objectives, the author's prior experiences, and discussions with colleagues in accounting and other disciplines. In particular, the instructions are expanded and improved each semester, based on experiences and issues identified in the previous semester. The instructions may seem excessively detailed, but experience indicates that students in this course need detailed guidance, especially for interaction with the interview subjects. Interview subjects have commented in recent semesters that student groups seem better prepared for the project, likely the result of increasing detail in the instructions.

\section{EXHIBIT I \\ GROUP OUT-OF-CLASS PROJECT \\ Accounting XXX \\ Winter 2005}

This semester your group out-of-class project will be to interview a member of our Accounting Advisory Board in his/her office, to gain insight into the importance of the Accounting function in business. Board members all hold very responsible positions in industry or public accounting, and can provide valuable insights.

This is a group project. To receive credit for the project, you must participate in the interview, contribute to preparation of your group's written report, and participate in the oral presentation of your group's findings and conclusions. (Note - If it is impossible for everyone to participate in the interview, you may still receive credit if you participate in all other activities, and the other group members agree that you performed an appropriate share of the work. However, you must receive prior approval and justify in the written report why you did not attend.)

The following "calendar" describes the specific dates and activities: 
- $\quad$ February 11 - Group assignments made. Every student will be randomly assigned to a group by your instructor. Also, at this time each group's interview subject will be identified.

- $\quad$ February 11 to February 25 - Contact interview subject (contact may be by phone or by e-mail) and arrange a time for a one-hour interview in the subject's office. Be sure to clearly identify yourselves as students in this class. Remember that the interview subjects are quite busy and have limited availability. After agreeing on a time, prepare and send a business letter to the subject confirming the appointment for the interview visit.

- $\quad$ February 28 - Submit a copy of your group's business letter to your interview subject. Also, submit the list of prepared questions (see next item). If any member of the group cannot participate in the interview, at this time that person must submit a letter to your instructor explaining why he/she cannot participate and requesting advance approval.

- $\quad$ February 28 to April 1 - Conduct the interview in subject's office. Remember, you are going to a business location. Dress appropriately. Every group member must participate in the interview. In preparation, before going to the interview PREPARE several questions for the interview subject. Assign at least two different questions to each group member. (This list of questions must be submitted with the confirmation letter.)

- $\quad$ April 18 - Written report due.

- $\quad$ April 20 and 22 - Oral presentations in class.

\section{Interview Objective}

Each group will interview their subject to learn about the importance of Accounting in the business community. Consider both external reporting (financial statements) and internal (managerial) accounting. Also, you should obtain information about your subject to help you understand his/her career path. Your report should include information about your subject and his/her position (title, job description, educational background, experiences prior to current position, etc.). Your prepared questions should also include other areas, such as advice for students beginning their studies in the business school.

\section{Written Report}

Prepare a 3-5 page written report, describing what you learned. You should also include any surprises and changes in opinion due to the interview. Detailed instructions for the report will be distributed later.

\section{Oral Report}

Each group will make a 10-15 minute presentation in class, to share what you learned with classmates. Each member of the group must participate in the oral presentation. PLAN AND REHEARSE YOUR PRESENTATION.

\section{Inactive Group Members}

It is the individual student's responsibility to be active in the group. Be sure you have contact information (phone numbers, e-mail) for all group members, and that YOU interact with your group. If a group member fails to do his/her share of the work, the other members of the group should inform the instructor and the inactive group member will receive no credit for the project.

\section{Assigning Students To Groups And Groups To Interview Subjects}

In assigning students to groups and groups to interview subjects, the following issues are addresses: 1) The number of students per group; 2) When to make group assignments and conduct the project; 3) How to assign students to groups; and 4) How to assign groups to interview subjects. 
With the objective of ensuring that the number of students participating in the interviews would be small enough to allow participation by all members, but large enough to make the interview subjects feel it was a meaningful experience, the author concluded that 6-8 students per group would be appropriate.

Given the desire to maintain viable groups, and in light of the traditional attrition rate in the Introductory Accounting course, group membership is not assigned until after the first examination (roughly one-third of the semester). This does reduce the time available for conducting the interview. However, it excludes the students who withdraw early in the semester. Other methods are used to minimize the effect of students withdrawing (officially or "unofficially") later in the semester.

Students are not permitted to self-select groups; group membership is assigned by the instructor. The assignment process is not random. To provide the benefit of strong students working with weaker students (and because weaker students are more likely to withdraw), each group contains a mix of strong, average, and weak students. The students are ranked according to their grades on the first exam, and each group is assigned students with "high" grades, "medium" grades, and "low" grades on the examination. Further, to encourage working with new individuals, the author attempts to assign obvious friends to different groups. Groups are assigned to interview subjects on a random basis.

\section{Follow-Up Communication And Evaluation}

After the assignments are completed and presented, each student group is required to send a thank-you letter to its interview subject. In addition, the author sends a thank-you letter and a survey instrument to the interview subjects. A survey instrument is also distributed to all student participants. The results of those surveys are discussed below.

\section{OUTCOMES AND ASSESSMENT}

In all semesters during which this project has been used, every group successfully completed the assignment and prepared acceptable written and oral presentations, and each individual group member who remained active participated in an oral presentation. Admittedly, many groups lost members, and some groups prepared and presented better papers and presentations. However, no group failed to perform at an acceptable level. In evaluating whether the assignment achieved its objectives, the author considers the contents of the written and oral presentations, and the students' and interview subjects' responses to the follow-up survey instruments.

In the written and oral presentations, groups/individuals have commented on the extent to which the interview subjects and their work-places differ from expectations. In fact, a number of students have indicated that they have a more positive attitude toward accounting as a career after this experience. Conversely, a few have stated that the visit to the interview subject's office confirmed that they did not want a career in accounting. It was probably good that they made the discovery at this stage of their education.

To better evaluate the assignment, survey instruments were designed and distributed to all student participants and all interview subjects. While the interview subjects' responses are identified, the students' responses are anonymous.

One of the primary objectives of the survey is to obtain suggestions for improving the exercise in future semesters, so the questions in the survey are generally open-ended and intended to obtain comments. The results are not appropriate for detailed statistical analysis. The responses provide information about each participant's experiences, attitude toward the assignment, and perceptions of a career in accounting.

Student participants are asked questions addressing the most informative, the most surprising, and the most frustrating aspects of the assignment, suggestions for improving the assignment, and their perceptions of an accounting career. The interview subjects are asked whether they would be willing to participate again, questions addressing the most interesting and frustrating aspects of their experience, and suggestions for improvement. 


\section{Survey Results}

The attitudes of both the students and the interview subjects are quite positive toward the exercise. The students felt the most informative aspect of the assignment was the opportunity to visit with the interview subject in his/her office. They also found the opportunity to meet with a highly successful professional or corporate manager very informative. The most surprising information learned was the nature and breadth of the responsibilities of the professional accountant, and in particular the need for "people skills" at that level. Even for those students who had no plans to major in accounting, there was a general attitude that the exercise was quite valuable.

For the students, the most frustrating aspect was the scheduling necessary for the group to meet, and to meet with their interview subject. A few complaints about the unequal sharing of the workload, which seems to be a common complaint for all group projects, have also been made. Also, there have been a few complaints about having to travel to the interview subject's office. However, since $90 \%$ of students commute to campus, the author concluded this was not a transportation problem. Likely, this too was a scheduling problem, exacerbated by the need to coordinate with the interview subject during working hours.

Overall, there was a very positive attitude on the part of the students toward the assignment. In fact, when asked for suggested changes on the survey, a majority of students responded that no changes were necessary. Almost every suggested change has to do with improving the scheduling issue, such as providing more class time for the groups to meet and extending the time available for the project.

A majority of the class members had not planned to major in accounting when the class began. When asked whether the assignment had changed their attitude toward an accounting career, many responded that their intended major had not changed. However, there was a general change in the perception of an accounting career. In particular, the fact that these accountants work with people much more than with numbers was a surprise. There have been a number of responses that indicated a higher interest in an accounting career. A much smaller number of responses indicated that their aversion to an accounting career was confirmed.

The interview subjects are all quite willing to participate in future semesters, and all felt the assignment was valuable for the students. One partner of a large regional CPA firm found it interesting "watching young wide-eyed students being introduced to a live business environment - many (most?) for the first time". Another felt it was "an excellent program ... unique to [the author's university]".

\section{CONCLUSION}

Overall, the author was satisfied with the group assignment described here. While many of the specific elements of this exercise were designed to address the circumstances at the author's institution, the general concept should transfer well to other institutions.

\section{BIBLIOGRAPHY}

1. Accounting Education Change Commission, The First Course in Accounting: Accounting Education Change Commission Position Statement No. Two, AECC, Torrance, CA, June, 1992.

2. Colbeck, Carol L., Campbell, Susan, and Bjorklund, Stefani A., Grouping in the Dark: What College Students Learn from Group Projects, Journal of Higher Education, Vol. 71, No. 1, 2000.

3. Cowan, T. K., Accounting in the Real World, Accounting and Business Research, Autumn 1983.

4. Davis, Barbara D. and Miller, Thomas R., Job Preparation for the $21^{\text {st }}$ Century: A Group Project Learning Model to Teach Basic Workplace Skills, Journal of Education for Business, Vol. 72, No. 2, 1996. 
5. Lordan, Edward J., Using Group Projects to Help Students Sharpen PR Skills, Public Relations Quarterly, Vol. 42, No. 2, Summer 1996.

6. Muller, Thomas E., Assigning Students to Groups for Class Projects: An Exploratory Test of Two Methods, Decision Sciences, Vol. 20, No. 3, Summer 1989.

7. Schoenecker, Timothy S, Martell, Kathryn D., and Michlitsch, Joseph F., Diversity, Performance, and Satisfaction in Student Group Projects: An Empirical Study, Research in Higher Education, Vol. 58, No. 8, 1999.

8. Schwartz, Bill N., Introducing Accounting Students to the Real World, Woman CPA, April 1980.

\section{GROUP OUT-OF-CLASS PROJECT \\ ADDITIONAL INSTRUCTIONS \\ Accounting XXX \\ Winter 2005}

Written Report - Due April 18, 2005

Your written report MUST be prepared according to the following instructions

1. Your report should address all the objectives per the assignment sheet.

2. It should be 3-5 pages, printed on $81 / 2$ " by 11" paper. Do not use a binder or report cover. Staple the sheets together in the upper left corner. Attach copies of your letter confirming the interview and your thank-you letter to the person interviewed (of course, you send a thank you letter).

3. Prepare a cover sheet which includes the name of the interview subject and the names of all ACTIVE group members. If an individual was assigned to the group but did not participate, do not list him/her on the cover sheet. In the written report, do state that he/she was INACTIVE.

4. The Interview - Specifically identify those group members who DID participate in the interview and those who DID NOT participate in the interview. For each group member who did not participate, include a statement justifying why they did not participate, and why they should still receive credit.

5. The written report is a GROUP project. EVERY group member must participate in the writing or the editing of the report. Include a statement indicating what each group member did in preparing the written report.

Oral Presentation - April 20/22, 2005

Your oral presentation MUST satisfy ALL requirements per the assignment sheet. Specifically, the following must be considered for the oral presentation:

1. All group members MUST participate in the oral presentation. Presenting before a group is an important (individual) objective of the project. (If you must miss that day - the reason had better be REALLY good), an opportunity for a make-up oral presentation - at the beginning of the final examination period - may be permitted. See your instructor.)

2. The oral presentation should be a COORDINATED effort, not a series of individual talks. Lack of coordination will significantly reduce the project grade. Hint: PRACTICE AS A GROUP.

3. Content - Your oral presentation should of course include information about your interview subject, but you should also share with classmates any information you found useful for career planning or otherwise especially interesting.

4. Your presentation should be practiced, not just read from a script. In particular, merely reading the written report is NOT acceptable.

5. Your presentation must fall within the 10-15 minute time period, in order to allow all groups to present.

When You Are Not Presenting (Listening to other groups' presentations) 
You have a responsibility to be present when other groups present. Absence on the day you are not presenting will result in a 20 point deduction from your individual score on the group project. Every class member also has a responsibility to listen carefully to the other groups and not be distractive. Such behavior will also result in a reduction of your individual score.

\section{NOTES}

